\title{
INVESTIGATION OF PILES BEHAVIOR UNDER LATERAL CYCLIC LOADING
}

\author{
Chunhui Liu ${ }^{1 *}$ - Liang Tang ${ }^{1}-$ Xianzhang Ling ${ }^{1,2}$
}

${ }^{1}$ School of Civil Engineering, Harbin Institute of Technology, Harbin, Heilongjiang, 150090, China.

${ }^{2}$ School of Civil Engineering, Qingdao Technological University, Qingdao, Shandong, 266033, China.

\begin{tabular}{l}
\hline ARTICLE INFO \\
\hline Article history: \\
Received: 20.9 .2016$. \\
Received in revised form: 26.11.2016. \\
Accepted: 28.11.2018. \\
\hline Keywords: \\
Piles \\
3D finite element analysis \\
Cyclic lateral load \\
Numerical models \\
\hline DOI: http://doi.org/10.30765/er.39.3.01
\end{tabular}

\section{Introduction}

Pile foundations are commonly used to support various important structures such as bridges, highways, and tall builds. These kinds of structures are usually subjected to cyclic lateral load caused by wind, waves, and earthquakes. In order to investigate pile behavior under lateral load, few experiments have been conducted. For example, Brown et al. [1] finished large-scale lateral loading tests on a $3 \times 3$ pile group and an isolated single pile that were constructed in dense sand and stiff clay. Morrison and Reese [2] finished similar tests on $3 \times 3$ pile group in medium dense sand. Similarly, Rollins et al. [3] finished full scale lateral load tests on $3 \times 3,3 \times 4$ and $3 \times 5$ pile groups that were located in sand and on clay ground. McVay et al. [4] studied pile group behavior in medium loose and medium dense sand ground using centrifuge tests. However, due to the high costs and logistical difficulty of conducting cyclic lateral load tests on the pile groups, most of these full-scale and centrifuge load tests are focused on a narrow

\begin{abstract}
:
In this paper, the capability of $3 D$ nonlinear finite element models is validated by single pile and $5 \times 3$ pile group filed experiments that is subjected to cyclic lateral loading. Then, a series $3 D$ finite elements models are built to analyze the effect of the number of cycles of lateral loading, pile spacing, and pile group arrangement. The results have shown that the number of cycles affected the pile-soil system stiffness seriously, and the pile group effect became insignificant as the increase of pile spacing, while this effect became more significant with the increase of the pile group arrangement. In practical engineering, the pile spacing and pile group arrangement should be considered and chosen carefully.
\end{abstract}

aspect of this problem. For example, most of the experiments were performed on $3 \times 3$ free-head pile groups with the center-to-center spacing of three pile diameters $(D)$, and most of the experiments did not consider the effect of pile type, pile group configuration, pile spacing and so on.

Numerical method, such as finite element (FE) method, plays an important role in studying the behavior of pile subjected to lateral load and is much cheaper than the field and centrifuge tests. There are numerous studies in the literatures concerned with the application of the FEM for piles subjected to lateral cyclic loads [5-9]. However, the main purpose of the research is to validate the proposed constitutive model or developed algorithm. Few of them attempted to analyze the behavior of piles subjected to cyclic lateral load and to investigate the factors affecting the behaviors.

In view of this, a series of FE models have been established to systematically analyze pile group and single pile behavior under cyclic lateral load. In the presented paper, the capability of the 3D nonlinear

\footnotetext{
* Corresponding author.

E-mail address: mkhabiri@yazd.ac.ir.
} 
FE model in predicting pile behavior is firstly validated by full-scale field tests on a $5 \times 3$ pile group and single pile. After that, based on the capability of the proposed numerical method, the parameters that affect the response of piles under cyclic lateral load, such as the number of cycles of lateral loading, pile spacing, and pile group arrangement, are studied systematically.

\section{Brief descriptions of the full-scale field experiments}

Two full-scale in-site tests on a single pile and $5 \times 3$ pile group subjected to multistage cyclic lateral loading were conducted by Walsh [9] of Brigham Young University. The test site was located near the Salt Lake City International Airport. The $5 \times 3$ pile group experimental setup is show in the Fig. 1. For the two tests, all piles were made of steel pipes, with an outer dimension of $324 \mathrm{~mm}$, a wall thickness of $9.5 \mathrm{~mm}$. The total length of tested piles was 13.683 $\mathrm{m}$, and the parts of the above ground surface were 483 $\mathrm{mm}$. The pile moment of inertia $(I)$ was $1.43 \times 108$ $\mathrm{mm}^{4}$ for piles of the two tests. For the pile group, the pile spacing was $3.92 D$ (pile diameter) in longitudinal $(x)$ direction and $3.29 D$ in transverse $(y)$ direction, respectively.

Cone penetrometer test (CPT), standard penetration test (SPT), pressuremeter test (PMT), vane shear test (VST) and general laboratory tests were conducted to determine the soil classifications and parameters of the test site [9]. According to the results of the above tests, the soil profile used in numerical computer model can be idealized as follows: $0-2.4 \mathrm{~m}$ refilled sand, $2.4-4.6 \mathrm{~m}$ soft clay, $4.6-6.3 \mathrm{~m}$ sand, $6.3-8 \mathrm{~m}$ soft clay, and below $8 \mathrm{~m}$ sand. The depth of water table was $2.1 \mathrm{~m}$.

The test was performed using a displacement controlled approach, the target displacements were 6, $13,19,25,38,51,64,76$, and $89 \mathrm{~mm}$ which were applied ten times respectively. The lateral load was applied slowly, which can be considered as static load. Due to an accident that happened during the application of $51 \mathrm{~mm}$, the data of $51 \mathrm{~mm}$ and above are not reliable. The pile behavior under target displacements of $6,13,19,25,38 \mathrm{~mm}$ were analyzed during the numerical calculation.

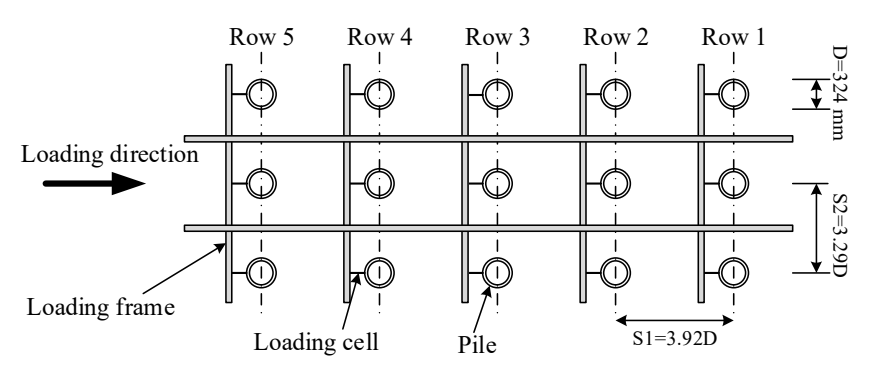

Figure 1. In-site experimental setup (after Walsh).

Table 1. Parameters of soil model

\begin{tabular}{ccccccc}
\hline Soil layer & $\begin{array}{c}\text { Thickness } \\
\text { of layer }\end{array}$ & $\begin{array}{c}\text { Density } \\
\left(\mathrm{t} / \mathrm{m}^{3}\right)\end{array}$ & $\begin{array}{c}\text { Shear } \\
\text { modulus }(\mathrm{kPa})\end{array}$ & $\begin{array}{c}\text { Poisson's } \\
\text { ratio }\end{array}$ & $\begin{array}{c}\text { Cohesion } \\
(\mathrm{kPa})\end{array}$ & $\begin{array}{c}\text { Friction } \\
\text { angle }\left({ }^{\circ}\right)\end{array}$ \\
\hline Sand & 2.4 & 1.67 & 55,000 & 0.4 & 0 & 40 \\
Clay & 2.2 & 1.91 & 87,000 & 0.4 & 30 & 0 \\
Sand & 1.7 & 1.81 & 105,000 & 0.4 & 0 & 38 \\
Clay & 1.7 & 1.91 & 129,000 & 0.4 & 30 & 0 \\
Sand & 8.0 & 1.67 & 155,000 & 0.4 & 0 & 40 \\
\hline
\end{tabular}

\section{The finite element model}

\subsection{The finite element mesh}

The above described single pile and $5 \times 3$ pile group in-situ cyclic lateral load tests were modeled using
OpenSees [10] that is an object-oriented, open-source FE analysis framework. The piles in single pile and pile group tests were all assumed to be linear elastic, while the soil domain behaved elastic-plastic under the cyclic loading. Only half of each model was meshed using symmetry considerations, as shown in 
Figs. 2a and $\mathrm{b}$. The soil domain was modelled by eight-node brick elements and the piles were modelled by beam-column elements and placed at their centers. As shown in Fig. 2c, the beam-column elements (rigid links) perpendicular to piles were used to represent the pile cross-sectional spatial domains (diameters).

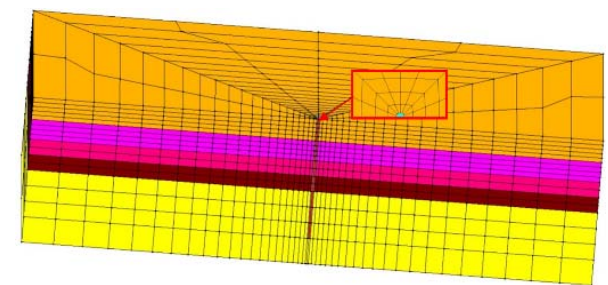

(a)

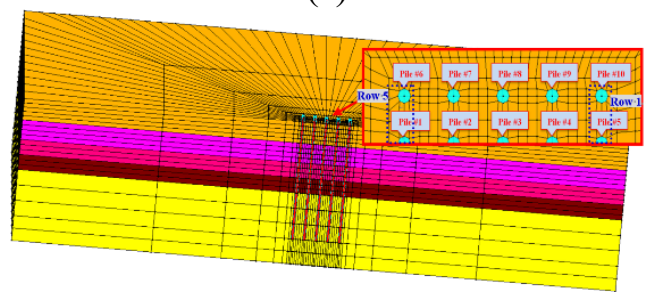

(b)

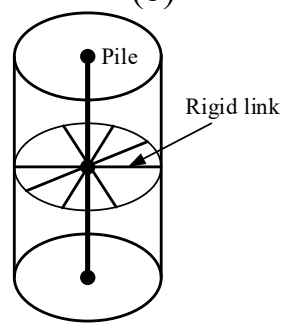

(c)

Figure 2. Finite element modeling: (a) single pile; (b) pile group; and (c) pile simulation.

The length of links were equal to pile radius, and 8 links were used around each pile node. Rigid links' nodes were tied away from pile centerline to the coincident nodes of the adjacent 3D soil brick elements in the three translational degrees of freedom using equalDOF constraints in OpenSees [11-12]. The other node of rigid link shared the same node with pile. These links were defined to $10^{4}$ time stiffer than the pile elements.

\subsection{Boundary condition}

The boundary conditions of single pile and pile group models were the same. The base boundary was modelled using fixed boundary, i.e., the longitudinal $(x)$, transverse $(y)$, and vertical $(z)$ directions were all fixed. The left, right and back sides of the models were fixed in $x$ and $y$ directions, which means that the soil domains could get deformed in vertical direction freely. The plane of symmetry was fixed in $y$ direction.

\subsection{The constitutive model}

Two kinds of soil constitutive models are used in this FE analysis. Pressure-IndependMultiYield constitutive model (PIMY) [13] and PressureDependMultiYield constitutive model (PDMY) [14] are chosen to describe the behavior of sand and clay respectively. These two models are based on multiyield-surface plasticity and formulated in effective stress space. The PIMY model is used to simulate monotonic or cyclic response of materials, such as, clay or organic soils. The shear behavior of this type of soils is insensitive to the confinement change. This constitutive model is an elastic-plastic model and the plasticity exhibits only in the deviatoric stress-strain response. The volumetric stress-strain response is linear-elastic and independent of the deviatoric response. A set of Von Mises yield surfaces with different sizes have been adopted in this model to define the hardening zone of the model. Nonlinear kinematic hardening and associative flow rules are employed to reproduce hysteretic behavior. The PDMY model is an elastic-plastic model which is used to simulate the essential response of pressure sensitive soil materials. In this model, a set of Drucker-Prager multi yield surfaces with a common apex that form the hardening zone of the model. Nonlinear kinematic hardening and non-associative flow rules are employed to reproduce the dilatancy effect. These two multi-surface models have been extensively calibrated and validated using on various laboratory tests [15] and centrifuge test [16] and could be used to model soil behavior under static and dynamic loading.

\subsection{Soil parameters}

In the finite element model, PIMY constitutive laws are adopted to simulate behavior of soil layers 2 and 4 (clay), while the PDMY constitutive laws are employed to model behavior of soil layers 1,3 , and 5 (sand). Material constitutive parameters were determined for the five soil layers by SPT results and general laboratory sample test data (for example, undrained shear strength test, unit weight test, and gravity test.), all the original data could be obtained from reference [9]. The main soil parameters include the unit weight, shear modulus friction angle, and cohesion are listed in Table 1. For the clay (layers 2 
and 4), these soil parameters are sufficient to characterize completely the pressure independent model. In the case of the PDMY model, in addition to the parameters listed in Table 1, other parameters governing the dilatancy and contraction behavior cannot be measured directly using laboratory test. The recommended values given by $\mathrm{Lu}$ [17] were used in this analysis.

\section{Verification of numerical model}

\subsection{Single pile}

The comparison between the numerical calculations and the measured results reported by reference [9] is shown in Fig. 3.

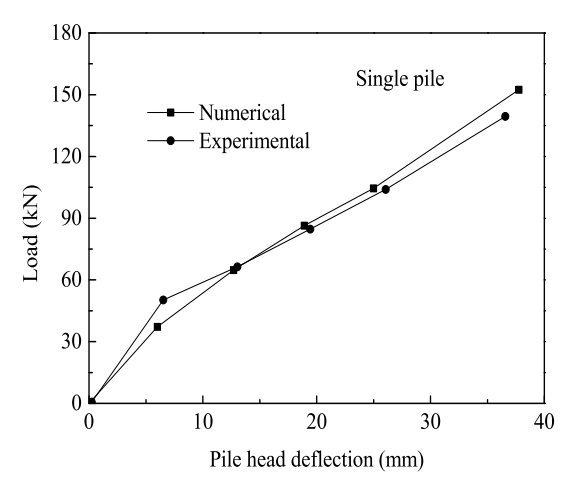

Figure 3. Load versus displacement time history at pile head.

There is an excellent comparison between the numerical results and the field test data. Even at larger displacements, the distinction between the numerical and the experimental results is less than $8 \%$, which is within reasonable limit in view of the variability of soil properties.

\section{$4.25 \times 3$ pile group}

The numerical calculations and experimental results of pile head load versus deflection for each row in the $5 \times 3$ pile group are presented in Fig. 4 . In general, good agreements are achieved between the numerical calculations and test results for each row of pile group. However, the numerical results of leading and second row are a little lower than the test results. The distinction between the numerical and the experimental results of the second row is less than $13 \%$, which is acceptable.
The numerical results of both single pile and pile group matched reasonably well the test data. Hence, it could be concluded that the numerical scheme adopted in the present investigation is capable of modeling the pile-soil interaction under lateral load.
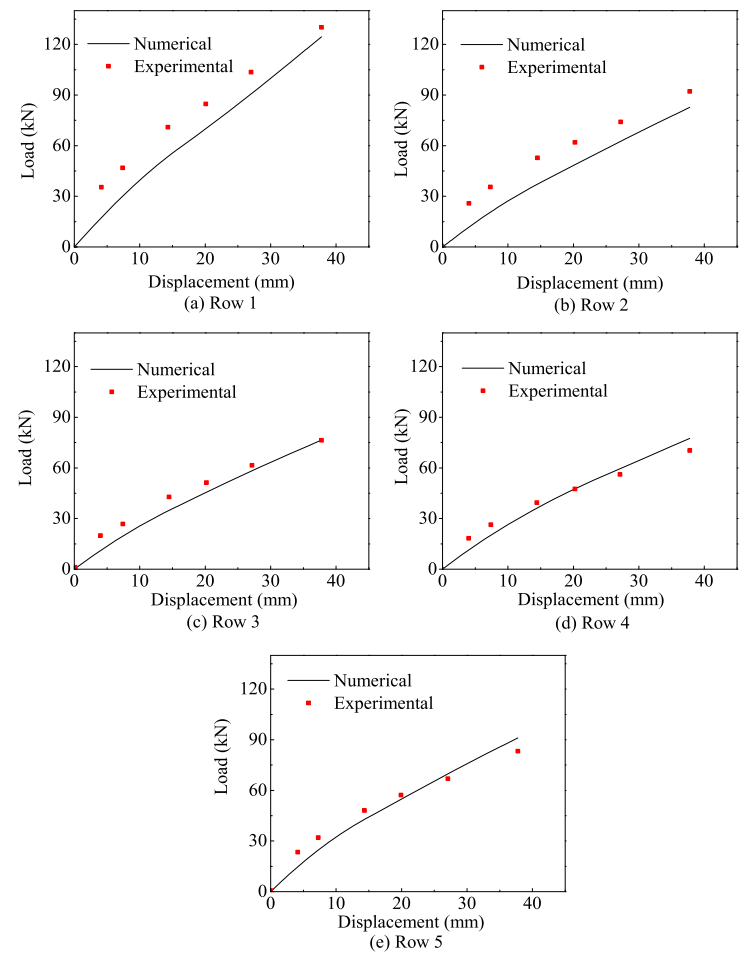

Figure 4. Numerical and experimental load versus displacement for each row in pile group.

\section{Parametric study}

Based on the numerical models mentioned above, a series of numerical models were developed to investigate the effect of number of cycles of load, pile spacing, and number of piles in group. The models were designed as follows:

(1) Effect of number of cycles of load: single pile with number of lateral cyclic load 10 times, and target loading displacements $6,13,19,25,38 \mathrm{~mm}$.

(2) Effect of pile spacing: $5 \times 3$ pile group with S/D (spacing to diameter ratio) equal to 2 to 8 , number of lateral cyclic load 10 times, and target loading displacements $6,13,19,25,38 \mathrm{~mm}$.

(3) Number of piles in pile group: $1 \times 2,2 \times 2,3 \times 3,5 \times 3$ pile group with $\mathrm{S} / \mathrm{D}$ equal to 3 , number of lateral cyclic load 10 times, and target loading displacements $6 \mathrm{~mm}, 13 \mathrm{~mm}, 19 \mathrm{~mm}, 25 \mathrm{~mm}$, and 38 $\mathrm{mm}$. 


\subsection{Effect of number of cycles of loading}

Based on the numerical model mentioned above, the complete load versus pile head displacement time history is shown in Fig. 5. The peak load versus displacement under each cycle is shown in Fig. 6. From these two figures, it can be concluded that the load-displacement behaviour under the cyclic lateral load is highly nonlinear and as the increase of number of loading cycles, the degree of nonlinearity becomes stronger, which may be attributed to the decrease of pile-sand stiffness.

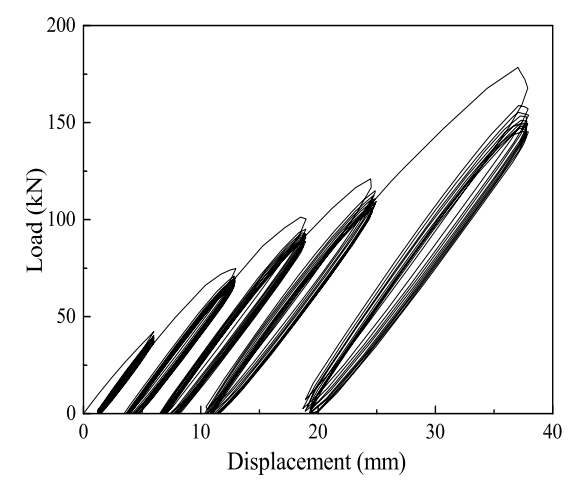

Figure 5.Complete load versus pile head displacement time history.

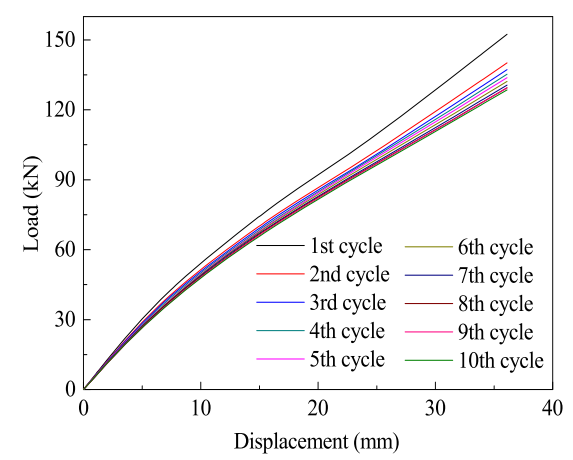

Figure 6. Pile head load versus pile head displacement of cycle 1 to cycle 10 for single pile.

In order to quantify the decrease system resistance with cyclic load, the definition of pile-soil stiffness $K$ given by the equation:

$$
K=\frac{\Delta F}{\Delta L}
$$

Where $\Delta F$ is the change in force between two sets of data and $\Delta L$ is the change in deflection corresponding to those forces. In other words, $\Delta F$ is merely the maximum load developed against the pile for a given cycle, and $\Delta L$ is the deflection at the same time step. The average of normalized stiffness with cycle number at various target deflection is shown in Fig. 7. In general, the stiffness of soil-pile system reduces as the increase of number of loading cycles at various target displacements, and nearly half the loss of stiffness that occurred in all ten cycles takes place during the first cycle.

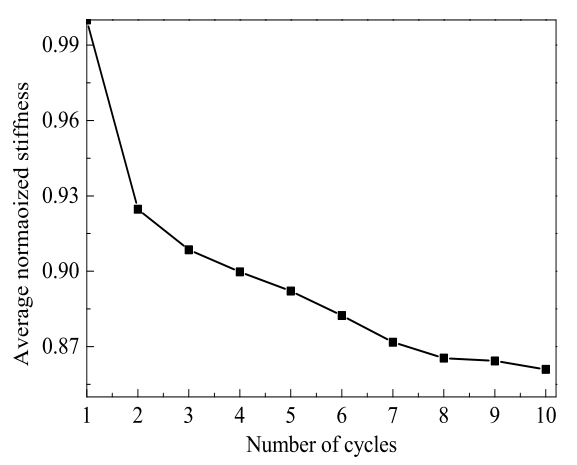

Figure 7. The average of normalized soil-pile stiffness with the cycle number at various target displacements.

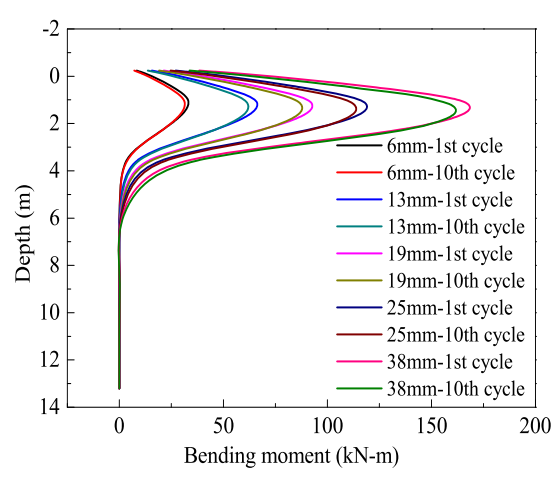

Figure 8. Bending moment versus depth at various target displacements for cycle 1 and cycle 10.

Comparison of bending moment versus depth at various target loading displacement $(6 \mathrm{~mm}, 13 \mathrm{~mm}$, $19 \mathrm{~mm}, 25 \mathrm{~mm}, 38 \mathrm{~mm}$ ) for cycle 1 and cycle 10 is presented in Fig. 8. For each target displacement, the first cycle requires the pile to sustain more bending 
moment than the corresponding tenth cycle, which is due to the soil soften effect adjacent to the pile and development of the gap between pile and the surrounding soil. It is also observed that the depth of maximum bending moment point along the pile increases, as the development of target gets displaced. This is caused by the gap around the pile getting deeper, as the number of loading cycle increases.

\subsection{Effect of pile spacing}

The average pile head load versus displacement curves obtained from a $5 \times 3$ pile group (with various pile spacing) and a single pile are shown in Fig. 9. It should be noticed that the data of the pile group are averaged values. For a given target displacement (for example, $38 \mathrm{~mm}$ ), the load of the pile group with pile spacing $S / D=8$ is the largest one, while the pile group with $S / D=2$ sustains the least lateral load. This phenomenon is attributed to a group effect caused by overlapping of stress zones. For closely spaced pile groups (for example $\mathrm{S} / \mathrm{D}=2$ ), once the piles of group are subjected to lateral load, the entire soil enclosed by the pile group moves as a single block in one direction. Under the cyclic lateral load, the soil enclosed especially by the piles of group is remodelled and softened. While, for the large spacing pile group, the portion of the soil between thegroup of pile is relatively uneffected. This is due to the fact that the distances between the piles are large enough. In view of this, the pile group effect becomes unobvious as the increase of pile spacing.

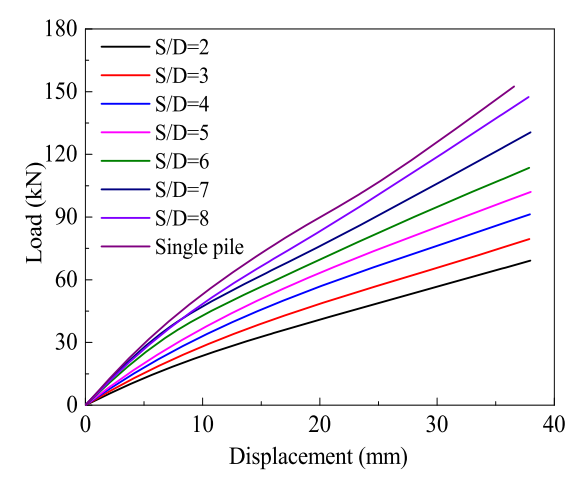

Figure 9. Load versus displacement for pile groups with different pile different spacing.

Fig. 10 shows the comparison of bending moment of single pile and pile group (averaged values) with various pile spacing. The bending moment of larger spaced pile group is highly larger than closely spaced pile groups, and the point of maximum bending moment of closely spaced group are deeper than pile groups with large spacing.

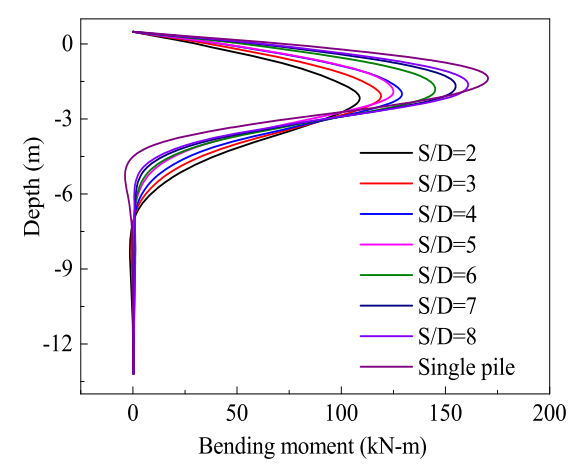

Figure 10. Bending moment versus depth for pile groups with different pile spacing.

It can also be concluded that the lateral load and bending moment of a single pile is larger than the average values of pile group with $S / D=8$. This means that the pile group effect does not disappear in $5 \times 3$ pile group when a distance between piles increases to $S / D=8$. In other words, the critical pile spacing of a $5 \times 3$ pile group is larger $\mathrm{S} / \mathrm{D}=8$, and this result is different with the conclusions obtained from $1 \times 2$, $1 \times 4$ and $2 \times 2$ whose critical piles' spacings are $5 \mathrm{D}$, $6 \mathrm{D}$ and $7 \mathrm{D}$ respectively [18].

As mentioned in the conclusion above, the pile group effect reduced with the increase of pile spacing. Therefore, larger pile spacing is recommended during practical design of a pile group, if we want to increase the pile group efficiency and lateral capacity of pile group foundations.

\subsection{Effect of a pile group arrangement}

The plots of the average load versus pile head displacement of a single pile and $1 \times 2,2 \times 2,3 \times 3$ and a $3 \times 5$ pile group with a pile spacing equal to $3 \mathrm{D}$ are presented in Fig. 11. It should be noted that the values of the pile group are averaged. In comparison to the single pile, the average load per pile in the pile group is less than that of the single pile for the same pile displacement. This means that the nonlinear loaddisplacement behavior is more obvious as the pile group scale increases. It can also be obtained from the figure that as the pile groupscale increases, the distinction of load-displacement behaviour between 
the single pile and the pile group raises. This phenomenon can be explained as the increase of pile group effects the raise of pile group scale.

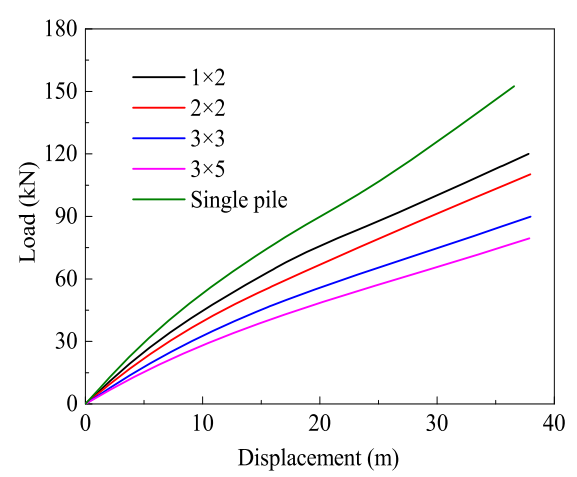

Figure 11. Comparison of pile head load versus displacement for pile group with various number of piles.

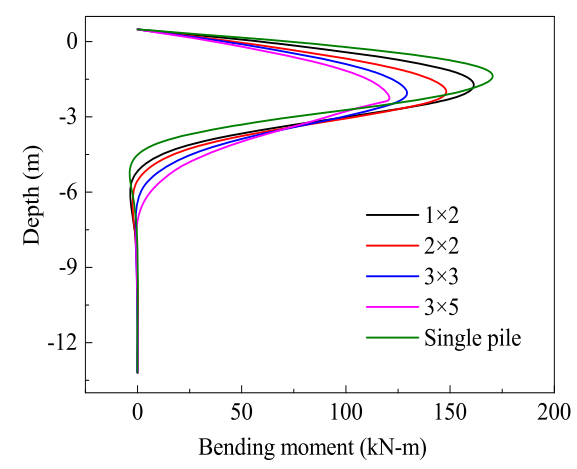

Figure 12. Bending moment versus depth for pile group with various numbers of piles.

The effect of number of piles in the pile group on average bending moment profiles is shown in Fig. 12. Bending moment of the single pile is much larger than that of the individual pile in the pile group. The maximum bending moment reduces

significantly as the numbers of piles increase in group. The increase in number of piles in the pile group leads to the occurrence of the maximum bending moment at deeper depth, as the stiffness of the pile-soil system reduces under the cyclic load. This phenomenon shows the pile group effect is much more significant as the pile group scale increases. The increase of the pile group effect is caused by the increase of overlapping stress zone of the pile group.
Based on the results of the load-displacement and bending moments of various pile group scale, it is clear that as the pile group scale increases, the pile group effect is more obvious. Thus, lateral bear capacity and efficiency pile group reduce significantly, so the scale of the pile group should be considered and chosen reasonably in the practical engineering.

\section{Conclusion}

The behavior of piles subjected to the cyclic lateral load has been investigated in the paper through a series of 3D nonlinear finite-element analyses. Based on the results from these analyses, the following conclusions can be drawn:

(1) The numerical scheme adopted in the present investigation is capable of modeling the behavior of a single pile and a pile group under the cyclic lateral load.

(2) The number of the cyclic lateral load affects the pile-soil system stiffness seriously. As the number of the cycle increases, the pile-soil stiffness reduces. Approximately half the loss of stiffness happens during the first cycle which occurs in all ten cycles.

(3) The soil pile interaction of pile group under the cyclic lateral load is seriously affected by the pile spacing. As the pile spacing increases, the pile head lateral load and maximum bending moment increase, which is close to the value of a single pile gradually. (4) As the pile group scale increases, the pile group effect is more significant which results that reaction of individual pile in a group reduces under the same target deflection and much less in comparison to the reaction of a single pile.

\section{Acknowledgments}

This work was supported by the National Natural Science Foundation of China (Grant nos. 51578195 and 51378161) and the Applied Technology Research and Development Plan Program of Heilongjiang Province, China (Grant no. GZ13A009).

\section{References}

[1] Brown, D. A., Reese, L. C., O'Neill M W.: Cyclic lateral loading of a large-scale pile group, Journal of Geotechnical Engineering, 113 (1987), 11, 1326-1343.

[2] Brown, D. A., Morrison, C., Reese, L. C.: 
Lateral load behavior of pile group in sand, Journal of Geotechnical Engineering, 114 (1988), 11, 1261-1276.

[3] Rollins, K. M., Lane, J. D., Gerber, T. M.: Measured and computed lateral response of a pile group in sand, Journal of Geotechnical and Geoenvironmental Engineering, 131 (2005), 1, 103-114.

[4] McVay, M., Casper, R., Shang, T. I.: Lateral response of three-row groups in loose to dense sands at $3 D$ and $5 D$ pile spacing, Journal of Geotechnical Engineering, 121 (1995), 5, 436441.

[5] Brown, D. A., Shie, C. F: Three dimensional finite element model of laterally loaded piles, Computers and Geotechnics, 10 (1990), 1, 59-79.

[6] Wakai, A., Gose, S., Ugai, K.: 3-D elasto-plastic finite element analysis of pile foundations subjected to lateral loading, Soil and Foundations, 39 (1999), 1, 97-111.

[7] Yang, Z., Jeremić, B.: Study of soil layering effects on lateral loading behavior of piles, Journal of Geotechnical and Geoenvironmental Engineering, 131 (2005), 6, 762-770.

[8] Dong, J., Shao, L.: Experimental study on deformation properties of unsaturated compacted soil based on digital image measurement, Engineering Review, 34 (2014), 3, 217-222.

[9] Walsh, J. M.: Full-scale Lateral Load Test of A $3 \times 5$ Pile, Thesis (M.S.), Brigham Young University, Department of Civil and Environmental Engineering, 2005.

[10] Mazzoni, S., McKenna, F., Scott, M. H., Fenves, G. L.: OpenSees command language manual, Pacific Earthquake Engineering Research (PEER) Center, 2006.

[11] Rollins, K. M., Brown, D. A.: Design guidelines for increasing the lateral resistance of highway- bridge pile foundations by improving weak soils, Transportation Research Board, 697, 2011.

[12] Elgamal, A., Yan, L., Yang, Z., Conte, J. P.: Three-dimensional seismic response of Humboldt Bay bridge-foundation-ground system, Journal of Structural Engineering, 134 (2008), 7, 1165-1176.

[13] Elgamal, A., Yang, Z., Parra, E., Ragheb, A.: Modeling of cyclic mobility in saturated cohesionless soils, International Journal of Plasticity, 19 (2003), 6, 883-905.

[14] Yang, Z., Elgamal, A., Parra, E.: Computational model for cyclic mobility and associated shear deformation, Journal of Geotechnical and Geoenvironmental Engineering, 129 (2003), 12, 1119-1127.

[15] Kammerer, A., Wu, J., Pestana, J., Riemer, M., Seed, R.,.: Cyclic simple shear testing of Nevada sand for PEER Center project 2051999, Research Report No. UCB/GT/00-02, University of California at Berkeley, California 2000.

[16] Dobry, R., Taboada, V., and Liu, L.: Centrifuge modeling of liquefaction effects during earthquakes, Keynote Lecture, Proceedings of the 1st International Conference on Earthquake Geotechnical Engineering (IS-Tokyo), 3 (1995): 1291-1324.

[17] Lu, J., Peng, J., Elgamal, A., Yang, Z., Law, K. H.: Parallel finite element modeling of earthquake ground response and liquefaction, Earthquake Engineering and Engineering Vibration, 3(2004), 1, 23-37.

[18] Chandrasekaran, S. S., Boominathan, A., Dodagoudar, G. R.: Group interaction effects on laterally loaded piles in clay, Journal of geotechnical and geoenvironmental engineering 136(2009), 4, 573-582. 